abnormal vessels which form an integral part of the lesion forming a 'haemangioneurofibroma'. Such pathology could explain the profuse bleeding encountered when excising this lesion.

Malignant conversion to a sarcoma has been described in plexiform neurofibromas but these have been in children with the other signs of neurofibromatosis. ${ }^{4}$ Our patient will be reviewed indefinitely because the neurofibroma may recur, although the full syndrome of von
Recklinghausen's neurofibromatosis is unlikely to develop at this age.

1 Boltshauser B, Stocker H, Sailer H, Valavanis A. Intracranial abnormalities associated with facial plexiform neurofibromas in neurofibromatosis type I. Neurofibromatosis $1989 ; 2: 274-7$.

2 Porterfield JF. Orbital tumours in children: a report on 214 cases. Int Ophthalmol Clin 1962; 2: 319-35.

3 Littlewood AH, Stilwell JH. The vascular features of plexiform new neurofibroma with some observations on the importance of pre-operative angiography and the value of pre-operative intra-arterial embolisation. BrF Plast Surg 1983; 36: 501-6.

4 Chaudhuri B, Ronan SG, Manaligod JR. Angiosarcoma arising in a plexiform neurofibroma: a case report. Cancer 1980; 46: $605-10$

\title{
Thelaziasis: report of two cases
}

\author{
T Shantikumar Singh, K Nareshkumar Singh
}

Regional Medical

College, Manipur, India

Department of

Microbiology

T S Singh

Department of

Ophthalmology

K N Singh

Correspondence to:

Dr T Shantikumar Singh,

Department of Microbiology,

NE Regional Medical College,

NE Regional Medical Coll
Lamphelpat - 795004

Manphelpat - 7950 India.

Accepted for publication 7 April 1993
We report here two cases of thelaziasis, a rare parasitic infestation of the eye in humans caused by a spiruroid nematode of the genus Thelazia. Although the total number of cases in the world is not available 28 cases, 17 from Japan, seven from China, two from Korea, and one each from Russia and India, have been reported. ${ }^{12}$ The complete life cycle of the nematode is not yet fully understood; however, a snail is considered to be a probable intermediate host. ${ }^{3}$ Burnett et al found a species of Fania to be a naturally and experimentally susceptible intermediate host for the larval development of Thelazia californiensis. ${ }^{4}$ A case of unilateral conjunctivitis caused by the same species was described by Knierin and Jack and it was thought that a fly or gnat was the possible mode of transmission in the Siskiou mountains of North California. ${ }^{5}$ Generally, the clinical manifestations of human thelaziasis comprised conjunctival congestion, pain, excessive lacrimation, and irritation. In Australia it is called 'bung' or 'blue eye' because of congestion and chemosis; there it is caused by Filaria hebronema, another species of Thelazia. $^{6}$ Permanent scarification and fibrous opacities of the conjunctiva and cornea may develop due to the presence and repeated movement of the worms.

\section{Case reports}

Two cases of thelaziasis have been seen in Manipur: an 18-month-old boy who presented with the complaints of excessive tears, irritation, and redness of the left eye of 6 days' duration; and a 3-year-old boy who suffered from a blunt injury to the left eye and presented with mild pain, irritation, and conjunctival congestion of 7 days' duration. On casual examination, the parents of both children had noticed thread-like moving worms on the affected eye. Clinical findings were similar and comprised conjunctival congestion, local oedema, and excessive lacrimation. No gross ulceration and follicles were seen; instead, there were whitish worms seen moving in the conjunctiva across the cornea. Routine examination of blood, urine, and stool revealed no abnormal findings. Two adult worms from each patient were removed from the conjunctival sac after instillation of $4 \%$ lignocaine hydrochloride. The worms were later identified as adult Thelazia callipaeda on the basis of the hexagonal mouth, absence of alae and cuticular ornamentations except for conspicuous transverse striations near the anterior end which are considered to aid movement across the smooth surface of the cornea. The infection in both cases might have occurred from close association with infected dogs or through house flies, Musca domestica.

\section{Comment}

Diagnosis depended on the recognition of creamy white worms coiled in the conjunctival sac or migratory worms over the cornea. Removal of the worms and morphological study under a dissecting microscope were needed for species identification. Complete removal of the worms with eye forceps provides a cure as no drug is yet known to be effective against the nematode. Because of the rarity of reports on human thelaziasis clinicians, apparently unaware of the condition in which spiruroid nematode infestation can give rise to such a clinical manifestation, might think of other causes of the conjunctivitis. Thorough and careful examination of the affected eye, bearing in mind the possibility of such a condition, would justify the recognition of more cases and the right treatment. 
1 Faust EC, Russel PF, Jung RC. In: Craig and Faust's clinical parasitology. 8th ed. Philadelphia: Lea and Febiger, 1974: 356-8.

2 Yamaguchi T. A colour atlas of clinical parasitology. 1st Ed. London: Wolf Medical, 1981: 170.

3 Duke-Elder S. System of ophthalmology. 2nd Ed. London: Kimpton, 1965: 416-7.
4 Burnett HS, Parmelee WE, Lee RD, Wagner ED. Observations on the life cycle of Thelazia californiensis. $\mathcal{F}$ Parasitol 1957; 43: 433.

5 Knierin R, Jack MK. Conjunctivitis due to Thelazia californiensis. Arch Ophthalmol 1975; 93: 522-3.

6 Manson-Bahr PEC, Apted FIC. Manson's tropical diseases. 18th Ed. London: Bailliere Tindall, 1982: 604 .

\title{
Sedation with nasal ketamine and midazolam for cryotherapy in retinopathy of prematurity
}

\author{
André Louon, Joan Lithander, Venu Gopal Reddy, Anil Gupta
}

Sultan Quaboos

University Hospital,

Muscat, Sultanate of

Oman

Department of

Anaesthesia

A Louon

V G Reddy

Department of

Ophthalmology

$J$ Lithander

Department of

Paediatrics

A Gupta

Correspondence to:

Dr A Louon, Room 2781,

Sultan Quaboos University

Hospital, PO Box 32488

Al-Khod, Muscat, Sultanate of

Oman.

Accepted for publication

17 March 1993
Sedation of infants in ophthalmology is a challenge for the anaesthetist. Often general anaesthesia is not required but a quiet and immobile patient is necessary if the examination/ treatment is to be successful.

We report on a 44 -day-old, $1 \cdot 3 \mathrm{~kg}$ baby who was to receive cryotherapy treatment for retinopathy of prematurity (ROP) and who was successfully sedated with nasal ketamine and midazolam. This simple and non-invasive method might be of interest to the paediatric ophthalmologist. More cases are required to assess its safety and reliability.

\section{Case report}

This surviving twin baby girl was born at 26 weeks of gestation with a birth weight of $770 \mathrm{~g}$. In the neonatal intensive care unit, she had bronchopulmonary dysplasia and suffered from respiratory distress syndrome, apnoea and bradycardic episodes, and septicaemia.

She was intubated and ventilated for 33 days and required oxygen therapy sometimes at a fraction of inspired oxygen of 1.0 for a total of 44 days. Episodes of bradycardia occurred throughout.

Ophthalmic check up revealed: right eye: ROP grade 2 in zone II, left eye: ROP grade 3 in zone II with plus disease (hyperaemia of the iris, vasodilatation, and tortuosity of the vessels in the fundus).

In view of this, cryotherapy was indicated. The parents refused their consent for general anaesthesia but agreed to sedation.

Preoperatively, apart from the ophthalmic problem, this baby had no neurological deficits, was breathing spontaneously, and had normal behaviour for age.

For the past 18 months, our department of anaesthesia has used nasal ketamine and midazolam for paediatric sedation in computer tomography with good results (Louon and Reddy unpublished data, under review). We decided that this technique could be used in this difficult patient.
On admission to the operating theatre, the baby was awake and not intubated. Monitoring included electrocardiography, oxygen saturation, a precordial radio stethoscope, and temperature. Intravenous access was available. An oxygen tubing was positioned in front of the baby's nares should oxygen be necessary.

A mixture containing midazolam $(5 \mathrm{mg} / \mathrm{ml})$ $1.8 \mathrm{ml}$, ketamine $(50 \mathrm{mg} / \mathrm{ml}) 1.6 \mathrm{ml}$, and normal saline $0.6 \mathrm{ml}$ (total $4 \mathrm{ml}$ ) was prepared and a dose of $0.25 \mathrm{ml} / \mathrm{kg}$ body weight given, half of the required volume $(0.4 \mathrm{ml})$ being instilled in each nostril. The total dose received was midazolam $0.9 \mathrm{mg}$ and ketamine $8 \mathrm{mg}$. Within 4 minutes, the child was properly sedated (drowsy, motionless, but not anaesthetised).

After topical anaesthesia with amethocaine chloride $1 \%$, transconjunctival cryotherapy of the avascular area in front of the ridge was performed with a broad tip in both eyes.

During the whole 12 minute procedure, the pulse rate remained between 140 and 150 with no episode of apnoea or bradycardia. Oxygen saturation remained, without oxygen, in the range of $94 \%$ except on two 30 second occasions when it dropped to $90 \%$. A short course of oxygen $(1 \mathrm{l} / \mathrm{min})$ increased it to $98 \%$. Operating conditions were excellent for the ophthalmologist without any untoward movements.

The postoperative period in the special care baby unit was uneventful except for one brief episode of bradycardia resolved by bag ventilation.

Ophthalmic assessment at discharge, 6 weeks after treatment, showed significant regression with ROP grade 1 in zone III in both eyes.

\section{Comment}

Anaesthesia for short non-invasive ophthalmic procedures in small babies poses a problem to the anaesthesia and ophthalmology departments.

If general anaesthesia is chosen, the baby will often be intubated. Because of limited space while the ophthalmologist is working, a mask cannot be applied, especially with low birth- 